\title{
Appreciation of Unique Anatomical Variations During a Laparoscopic Repair of a Hiatus Hernia in an Adult Patient with Heterotaxy Syndrome Allows a Safe Outcome
}

\author{
Walid E Abdel Rahim*, Sami Galaledin and Eltaib A Saad \\ Department of Surgery, University of Khartoum, Sudan
}

Received: June 25, 2018; Published: July 20, 2018

*Corresponding author: Walied E Abdulrahim, Fellowship of Liver Surgery and Transplantation, Assistant Professor of Surgery, University of Khartoum, Sudan, Email: walide45@yahoo.com

\begin{abstract}
Heterotaxy syndrome is a rare but well-known occurrence involving a complex entity of broad-spectrum anatomical anomalies that are associated with various visceral and vascular variants. Authors report an exceedingly rare case of a heterotaxy syndrome with polysplenia in a 44-year-male who underwent a laparoscopic hiatus hernia repair. Preoperative evaluation by a multi-detector computed tomography showed a right-sided stomach, a two-humped left-sided liver, polysplenia, a pre-pancreatic portal vein and an absent inferior vena cava with a direct continuation of the azygous and hemiazygous veins. During the laparoscopic repair following informed consent; the small intestines were normally positioned, and the pancreas was normal in both location and structure. One splenic mass on the left side was lying in the lesser sac beneath the left lobe of the liver and was obscuring the critical view of the esophageal hiatus and the gastric fundus was not redundant and difficulty identifiable, so a superior hiatal repair with Dor fundoplication was successfully performed as it was a safer option. Despite the rarity of such unusual occurrence, a careful preoperative identification of the anatomical anomalies, anticipation of operative challenges and considering alternative techniques are the key to achieve a safe outcome in the context of the aberrant anatomy.
\end{abstract}

Keywords: Anatomical variants; Laparoscopic hiatus repair; Heterotaxy syndrome; Polysplenia

\section{Introduction}

Heterotaxy in Greek literally means a different arrangement in space. Heterotaxy syndrome is a rare congenital condition that occurs from failure of intra-abdominal and/or intrathoracic organs to rotate correctly during embryologic development, resulting in abnormal arrangement of the organs across the left-right axis of the body [1]. It has two broad subcategories which include polysplenia and asplenia [1]. As most of patients remain asymptomatic; the prevalence of this anomaly remains underestimated, although one study has suggested that 1 in every 2500 people may have heterotaxy syndrome with polysplenia [2]. This condition is mostly detected incidentally in the adults during multi-detector computed tomography scanning for diagnosis of other pathologically related or unrelated complaints as in this reported case $[3,4]$. Herein authors report unusual anatomical findings that posed many operative challenges during a laparoscopic repair of a hiatus hernia in an adult patient with heterotaxy syndrome. Preoperative radiological evaluation and intra-operative appreciation of the anomalies with considering an alternative feasible technique allowed authors to achieve a safe outcome.

\section{Case Report}

A 44-year-old Sudanese male presented to our department with a long-standing history of challenging epigastric discomfort, heartburn and nocturnal chocking for 7 years. He had been using antacids and proton pump inhibitors without a remarkable improvement. He had no weight loss, anorexia, difficulty of swallowing, vomiting, or melena. He underwent three esophago-gastroscopies that revealed a large hiatal hernia with grade $\mathrm{C}$ reflux esophagitis. Biopsy revealed chronic inflammatory changes and was negative for any dysplastic or malignant changes. His past surgical history was significant for a para-umbilical hernia repair a year ago with uneventful postoperative course. Physical examination revealed an unusual hepatic dullness over the left upper quadrant area with a normal liver span and minimal epigastric tenderness. The rest of systemic examination was normal.

His general investigations (full blood count, random blood glucose, renal and liver profiles) were within normal ranges. His CXR showed normal lungs, levocardia and a right-sided 
gastric bubble. ECG revealed no abnormalities. A trans-thoracic echocardiography was normal apart from unusual drainage of hepatic veins directly into the right atrium. A multi-detector CT (MDCT) scan of the abdomen (with oral and intravenous contrast) confirmed the hiatus hernia (Figure 1) and revealed a right-sided stomach, a two-humped left-sided liver (Figure 2), polysplenia (three splenic masses, two on the left beneath the liver and one on the right) (Figure 3), a pre-pancreatic portal vein (Figure 4) and an absent inferior vena cava (IVC) with a direct continuation of azygous and hemi-azygous veins (Figure 5). Therefore, CT findings were consistent with heterotaxy syndrome with a left isomerism (polysplenia syndrome).

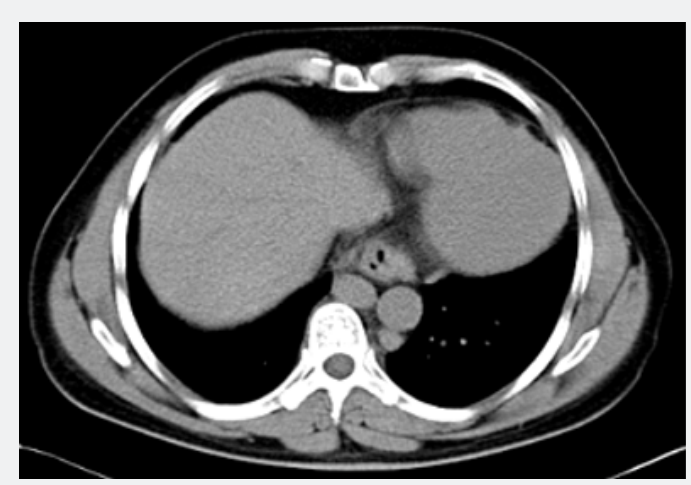

Figure 1: Axial CT abdomen with contrast showing hiatus hernia (evident by widening of the esophageal hiatus with cephalic gastric herniation).
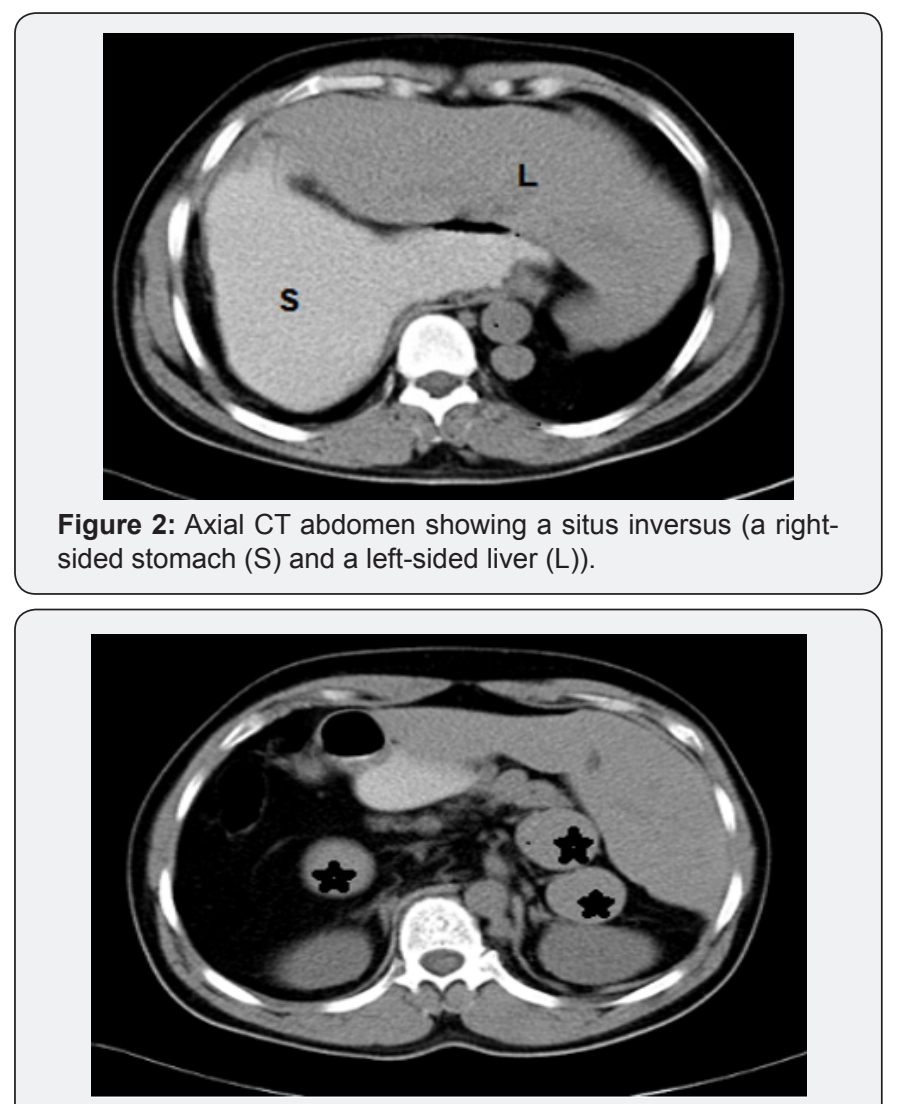

Figure 3: CT abdomen with axial view revealing Polysplenia (three black stars referring to isolated splenic masses).

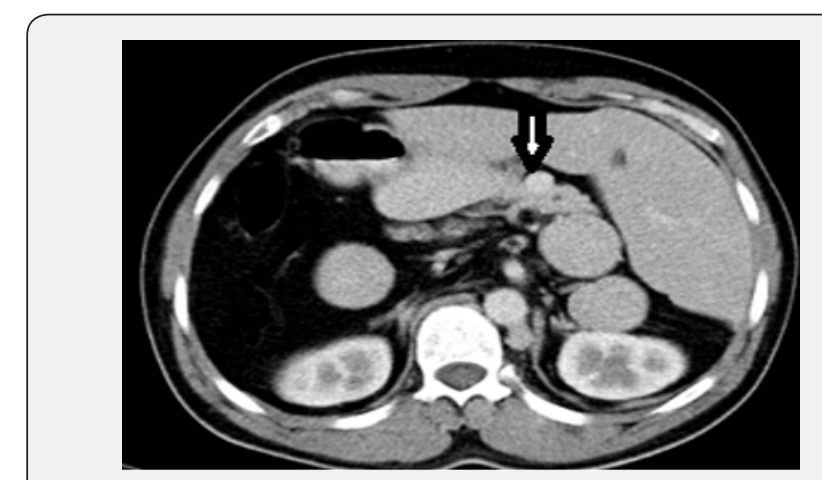

Figure 4: Axial CT abdomen (with oral and IV) contrast showing a prepancreatic portal vein (vertical arrow).

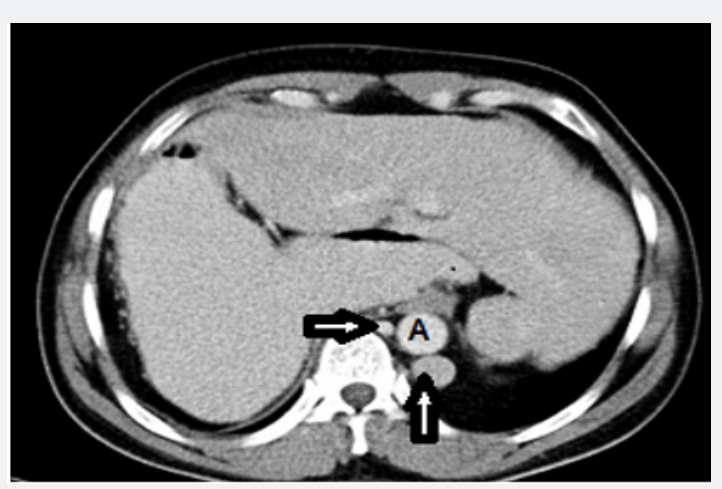

Figure 5: Arterial-based contrast-enhanced CT abdomen showing abdominal aorta (A), an absent IVC and direct continuation of azygous (vertical arrow) and hemi-azygous veins (horizontal arrow).

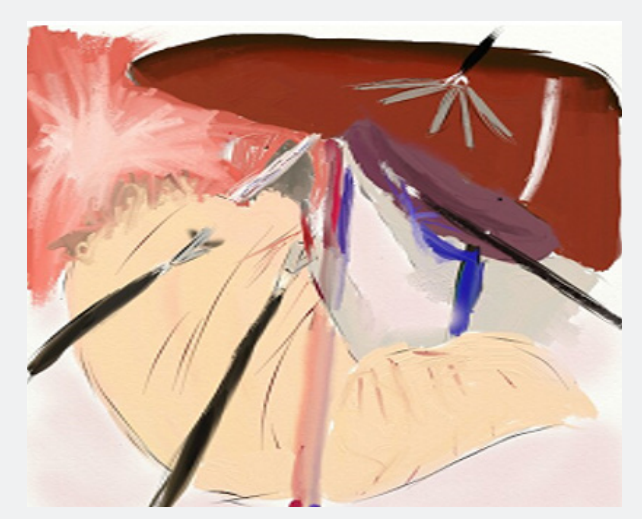

Figure 6: Schematic diagram represents intra-operative findings with a splenic mass in the lesser sac beneath the left lobe of the liver obscuring esophgeal hiatus critical view.

In view of his complaints; a laparoscopic repair of the hiatus hernia was planned. Following informed consent, he underwent a laparoscopic hernia repair. Patient was positioned in a supine position with both legs separated; Trendelenburg position with a 30-degree angle (but at certain steps a 45-degree position was adopted). Following pneumoperitoneum and during diagnostic laparoscopy, a few more findings were observed and deserved more attention; hepatic veins were draining directly into the right atrium and ductus venosus running from the left gastric vein into the right atrium. The small intestines were normally positioned. The pancreas was normal in both location and 
structure. Visualization of the esophageal hiatus was difficult as one splenic mass was lying in the lesser sac beneath the left lobe of liver obscuring hiatus hernia critical view (Figure 6).

Identification of the gastric fundus was challenging because of the unusual anatomy. The latter was not redundant enough to perform Nissen or Toupees fundoplication. Mobilization of the hernial sac through the esophageal hiatus was performed with a great caution. A Dor fundoplication $\left(180^{\circ}\right.$ fundoplication) was carried out as it was more feasible and safer technique. Hemostasis was achieved, and a drainage tube was placed through the infra-hepatic fossa. The patient had an uneventful postoperative course. He is in regular follow-up with no recurrence of his symptoms over a year.

\section{Discussion}

The exact etiology of heterotaxy polysplenia syndrome remains poorly understood. Nevertheless, a remarkable progress is achieved in understanding the genetic pathways responsible for left-right asymmetry in animal models [5] and some genes mutations (CFC1, SHROOM3) have been identified in patients with heterotaxy [6]. Understanding of various anomalies associated with heterotaxy polysplenia is crucial to avoid misdiagnosis of these anomalies or variants as pathological findings [3]. Additionally, an accurate pre-procedural evaluation is quite important before planning of surgical and interventional procedures, as appreciation of anatomical variants and their associated vascular and venous variations would hopefully minimize the occurrence of perioperative complications.

Although they are some previous reports of complicated pancreatic and hepatic surgeries in patients with heterotaxy syndromes that described technical difficulties and risks encountered during that operations because of the aberrant anatomy [7-10]; there are no previous reports of a laparoscopic hiatus hernia repair in a patient with heterotaxy syndrome in the reviewed English literature, and this reported case demonstrates the operative challenges and complexities that are usually faced during a surgical procedure that is already described as a kind of difficult surgeries in the field of laparoscopic hernias repair, that- in fact- requires a precise understanding of the surrounding anatomy of the gastroesophageal junction and esophageal hiatus [11].

Superior hiatal repair with $180^{\circ}$ Dor fundoplication (instead of a standard $360^{\circ}$ Nissen fundoplication) was a safer option in the context of technical and operative challenges encountered (obscured critical view by a splenic mass that was lying in the lesser sac and presence of anomalous venous vascular patterns and a pre-pancreatic portal vein which made dissection at the lesser momentum challenging). However, preoperative identification of these anatomical variants and predication of operative difficulties with considering alternative techniques allowed authors to perform a safe laparoscopic hiatus hernia repair.
The pattern of the associated anomalies depends on being a case of left or right isomerism. Right isomerism is consistent with asplenia, bilateral tri-lobed lungs, and more commonly cardiovascular anomalies, whereas left isomerism is associated with polysplenia, bilateral bi-lobed lungs and pancreatic anomalies with much lesser frequency of cardiac anomalies [1]. In fact, the occurrence of cardiac anomalies makes the patient susceptible to the development of congestive heart failure, so patients with right isomerism and asplenia have decreased survival compared to patients with left isomerism and polysplenia [1,3]. Multiple splenic nodules usually found along the greater curvature on the left or right sides [12]. In this reported case one splenic mass was lying beneath the left lobe of the liver and thus obscuring the critical view of the esophageal hiatus. Symptomatic polysplenia in adults is often caused by abnormal biliary and pancreatic duct drainage and small bowel obstruction [13], however, it was asymptomatic in this reported case. Interestingly, the pancreas was normal in position and structure in our patient, a finding that is reported in a similar report [3]. Nevertheless, literature has reported various pancreatic anomalies (short truncated pancreas, dorsal pancreas and pancreatic divism) that are associated with heterotaxy syndrome $[1,12]$.

Additionally, the small bowel was also normally positioned, in keeping with same pattern described before in a similar case [3], in contrast to other reports that found intestinal mal-rotation or non-rotation with heterotaxy patients $[1,7,14]$. Interrupted or absent IVC with azygous or hemi-azygous veins continuation is a constant associated finding with heterotaxy syndrome $[3,15]$. It is a venous anomaly in which there is an agenesis of retrohepatic segment of IVC and continuation through the azygous system by a persistent right supra-cardinal vein draining into superior vena cava $[3,6,16]$, with hepatic veins been directly draining into the right atrium.

In a similar report the hepatic veins converged into a virtually thin supra-hepatic IVC draining into the right atrium [9]. Another report described an exceedingly rare occurrence of a left-sided IVC with heterotaxy polysplenia syndrome [17]. Pre-pancreatic or pre-duodenal portal vein (PDPV) is a rare anomaly when the portal vein courses anterior to the pancreas and duodenum, and it is a well-known association with heterotaxy syndrome $[3,15-17]$. This venous anomalous is usually asymptomatic, however, it could rarely compress the common bile duct causing cholelithiasis which would be an indication for surgical intervention, and on that occasion a precise preoperative evaluation of PDPV anatomy with MDCT is mandatory to avoid any degrees of damage to this anomalous vein [18].

\section{Conclusion}

Heterotaxy syndrome is an exceedingly rare congenital anomaly that usually involves numerous visceral and vascular abnormalities encompassing multiple organ systems. It 
usually detected as an incidental finding during radiological examination for other pathologically related or unrelated complaints. Preoperative assessment should entail a through cardiopulmonary evaluation, as many associated cardiac and pulmonary anomalies can co-exist, and a detailed radiological assessment to appreciate anatomical and vascular variants before planning any surgical procedure for anticipation of operative difficulties that would be encountered. In this reported case, occurrence of unusual anatomical findings posed many technical challenges during a laparoscopic repair of a hiatus hernia, but a preoperative radiological evaluation and intraoperative appreciation of the anomalies with considering an alternative feasible technique allowed authors to achieve a safe outcome.

\section{References}

1. Pagkratis S, Kryeziu S, Lin M, Hoque S, Bucobo JC, et al. (2017) Case report of intestinal non-rotation, heterotaxy, and polysplenia in a patient with pancreatic cancer. Medicine 96(49): e8599.

2. Low JP, Williams D, Chaganti JR (2011) Polysplenia syndrome with agenesis of the dorsal pancreas and preduodenal portal vein presenting with obstructive jaundice-a case report and literature review. Br J Radiol 84(1007): e219-e22.

3. Shetty V, Paruthikunnan SM, Shatagar SG (2017) A Rare Case of Heterotaxy Syndrome Associated with Hepatolithiasis and Preduodenal Portal Vein. J Clin Diagn Res 11(11).

4. Kim S, Lee YS, Jung JH (2016) Anomalies of abdominal organs in polysplenia syndrome: multi-detector computed tomography findings. Korean J Radiol 74(2): 114-122.

5. Levin M (2005) Left-right asymmetry in embryonic development: a comprehensive review. Mech Dev 122(1): 3-25.

6. Tariq M, Belmont JW, Lalani S, Smolarek T, Ware SM (2011) SHROOM3 is a novel candidate for heterotaxy identified by whole exome sequencing. Genome Biol 12(9): R91.

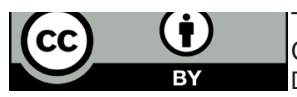

This work is licensed under Creative

Commons Attribution 4.0 Licens

DOI:_10.19080/OAJS.2018.09.555771
7. Lim HK, Choi YS, Lee SE, Kang H (2014) Pancreaticoduodenectomy performed in a patient with situs ambiguous accompanied with isolated levocardia, malrotation, and normal spleen. Ann Surg Treat Res 87(6): 340-344.

8. Meyer J, Rossetti A, Scheffler M, Morel P, Majno P (2013) Ampullectomy for an unexpected ampullary hamartoma in a heterotaxic patient. Int $J$ Surg Case Rep 4(6): 544-546.

9. Matsuda M, Amemiya H, Hosomura N, Ogiku M, Fujii H (2015) Hepatic resection for hepatocellular carcinoma in a patient with situs ambiguous with polysplenia: report of a case. Surg Today 45(6): 765771.

10. Sugimachi K, Ikeda Y, Taketomi A (2008) Extended hemi-hepatectomy with portal vein reconstruction in a patient with situs ambiguous. Case Rep Gastroenterol 2(1): 76-82.

11. Altorki NK, Yankelevitz D, Skinner DB (1998) Massive hiatal hernias: the anatomic basis of repair. J Thorac Cardiovasc Surg 115(4): 828-835.

12. Tawfik AM, Batouty NM, Zaky MM, Eladalany MA, Elmokadem AH (2013) Polysplenia syndrome: a review of the relationship with viscero-atrial situs and the spectrum of extra-cardiac anomalies. Surg Radiol Anat 35(8): 647-653.

13. Kapa S, Gleeson FC, Vege SS (2007) Dorsal pancreas agenesis and polysplenia/heterotaxy syndrome: a novel association with aortic coarctation and a review of the literature. JOP 8(4): 433-437.

14. Gayer G, Apter S, Jonas T, Amitai M, Zissin R, et al (1999) Polysplenia syndrome detected in adulthood: report of eight cases and review of the literature. Abdom Imaging 24(2): 178-184.

15. Rameshbabu CS, Gupta KK, Qasim M, Gupta OP (2015) Heterotaxy polysplenia syndrome in an adult with unique vascular anomalies: case report with review of literature. J Radiol Case Rep 9(7): 22-37.

16. Fulcher AS, Turner MA (2002) Abdominal manifestations of situs anomalies in adults. Radiographic 22(6): 1439-1456.

17. Jo DS, Jung SS, Joo CU (2013) A case of unusual visceral heterotaxy syndrome with isolated levocardia. Korean Circ J 43(10): 705-709.

18. Seo HI, Jeon TY, Sim MS, Kim S (2008) Polysplenia syndrome with preduodenal portal vein detected in adults. World J Gastroenterol 14(41): 6418-6420.

\section{Your next submission with Juniper Publishers will reach you the below assets}

- Quality Editorial service

- Swift Peer Review

- Reprints availability

- E-prints Service

- Manuscript Podcast for convenient understanding

- Global attainment for your research

- Manuscript accessibility in different formats

( Pdf, E-pub, Full Text, Audio)

- Unceasing customer service

Track the below URL for one-step submission https://juniperpublishers.com/online-submission.php 